\title{
Absorption of Lipid Hydroperoxides in Carp
}

\author{
Kazuhiko Hata, ${ }^{* 1,2}$ Kenshiro Fujimoto, ${ }^{* 1}$ and Takashi Kaneda ${ }^{* 1,3}$ \\ (Accepted August 19, 1985)
}

\begin{abstract}
The metabolic pathway of lipid hydroperoxides administered orally to carp was investigated in vitro and in vivo.

As the in vitro experiment, the decomposition products of 13-hydroperoxy-cis-9,trans-11octadecadienoic acid in reaction with the carp intestinal acetone powder were analyzed af ter methyl esterification. Four major compounds were isolated from the reaction mixture and were identified as methyl 13-oxo-cis-9,trans-11-octadecadienate, methyl 13-hydroxy-cis-9, trans-11-octadecadienoate, methyl 11-hydroxy-trans-12,13-epoxy-9-cis-octadecenoate, and methyl 9-hydroxy-trans12,13-epoxy-trans-10-octadecenoate.

In succession, $\mathrm{U}-{ }^{14} \mathrm{C}$-labeled methyl linoleate hydroperoxides were orally administered to carp, and the distribution of the radioactivity in the body was followed together with the transformation of hydroperoxides. After $24 \mathrm{~h}, 8.3 \%$ of the dosed radioactivity was retained in the body lipids, and hydroxyoctadecadienoate and oxooctadecadienoate were identified as the major products in several organs. Whereas, hydroperoxyoctadecadienoates were almost completely absent in carp organ lipids. These results suggest that most of the administered lipid hydroperoxides are absorbed in carp after the conversion into hydroxy or oxo derivatives in the intestine.
\end{abstract}

In a previous paper ${ }^{1)}$ the authors reported the toxic nature of methyl linoleate hydroperoxides (MLHPO) and their decomposition products on carp and noticed that both of them revealed toxic effects such as poor growth and musclar dystrophy known as "Sekoke" disease which accompanies an increase of carbonyl compounds in the lipids of intestine and adipose tissues. However, no accumulation of peroxides was recognized ${ }^{13}$ in contrast to the observation for rats ${ }^{2)}$ which accumulated a certain amount of peroxidized lipids in their tissues. The authors also noticed the decomposition of hydroperoxides and the formation of unsaturated carbonyls in the reaction of linoleic acid hydroperoxides with carp intestinal extract. ${ }^{3)}$ These observations suggested a metabolic pathway of orally administered lipid peroxides to carp in which most of the hydroperoxides are absorbed after decomposition in the intestinal tissues to carbonyl and other secondary products, and transported to the various parts of the body to cause damage.

Much work has been done on the decomposition mechanisms of lipid hydroperoxides both in enzymatic and non-enzymatic model systems, and various secondary products were isolated.
Although peroxidase activity was reported in the intestinal tissues of rats and rabbits ${ }^{4)}$ and hydroxy derivatives were identified in their lymph after oral administration of MLHPO, ${ }^{2,4}$ the decomposition mechanism of peroxides which leads to the formation of carbonyls and other secondary products in the intestine has not been available. On the other hand, Takeuchis) reported that considerable radioactivity was distributed to some organ lipids of carp dosed with $1{ }^{14} \mathrm{C}-\mathrm{MLHPO}$ orally. These combined results suggest the transformation of hydroperoxides into oxo and some secondary products in the intestinal wall prior to absorption. The present study deals with the identification of the decomposition products of linoleic acid hydroperoxides (LAHPO) either after the incubation with carp intestinal acetone powder in vitro (Experiment 1 ) or in the lipids extracted from some organs of carp being fed MLHPO or LAHPO (Experiment II).

\section{Materials and Methods}

\section{Experiment $I$}

Preparation of 13-Hydroperoxy-cis-9, trans-11Octadecadienoic Acid (13-LAHPO)

Silica gel (Silica Woelm TSC, Woelm Pharm.,

*1 Department of Food Chemistry, Faculty of Agriculture, Tohoku University, Sendai 980, Japan (楿 和 彦, 藤本煡四郎, 金田尚志: 東北大学農学部食糧化学科).

*2 Present address: Central Research Laboratory of Nippon Suisan Kaisha Ltd., Kitanomachi, Hachioji, Tokyo 192, Japan (日本水産 (株) 中央研究所).

*3 Present address: Koriyama Women's College, Kaisei, Koriyama, Fukushima 963, Japan (郡山女子大学). 
West Germany; $150 \mathrm{~g}$ ) was packed in a glass column $(1.6 \times 113 \mathrm{~cm})$ without addition of any solvent. Five $\mathrm{g}$ of autoxidized linoleic acid (peroxide value, $2000 \mathrm{meq} / \mathrm{kg}$ ) prepared as described in the previous paper ${ }^{3)}$ was applied to the column, and eluted with a mixture of hexane/ diethyl ether $(1: 1)$. The eluent was collected in every $5 \mathrm{~m} l$. The fractions which showed the positive spot test with $N, N^{\prime}$-dimethyl-p-phenylenediamine (DMPD) reagent ${ }^{3)}$ for peroxides were subjected directly to high pressure liquid chromatography (HPLC) ${ }^{7}$ to analyze the isomeric composition of LAHPO. The first DMPDpositive fraction (fr. 50-60) on dry column chromatography was found to be pure 13-hydroperoxy9-cis, 11-trans-octadecadienoic acid (isomeric purity, $98 \%$ ) by infrared (IR) spectrum, mass spectrum (MS) of its silylated (TMS) derivative after reduction with $\mathrm{NaBH}_{4}$ and methylation, and comparison of HPLC data in the literature. ${ }^{7)}$

\section{Decomposition of 13-LAHPO by Intestinal Acetone Powder}

U- ${ }^{14} \mathrm{C}-13-\mathrm{LAHPO} \quad(0.46 \mu \mathrm{Ci} / \mathrm{mmol}), 225 \mathrm{mg}$, was incubated with the carp intestinal acetone powder as described previously, ${ }^{3)}$ and the reaction products were extracted by the method of Bligh and Dyer. ${ }^{8)}$ Methyl esters of oxygenated products of fatty acids were applied to a dry silica gel column $(1.2 \times 125 \mathrm{~cm})$ packed with $85 \mathrm{~g}$ of silica gel (Silica Woelm TSC) whose moisture had been adjusted to $5 \%$ to obtain good reproducibility. The column was eluted with a total of $600 \mathrm{~m} l$ of the mixture of hexane/diethyl ether in which the concentration of diethyl ether was increased linearly from 20 to $100 \%$ and each $5 \mathrm{ml}$ of fraction was collected. Finally highly polar materials were recovered with $200 \mathrm{ml}$ of methanol. The radioactivity of each chromatographic fraction was determined by a liquid scintillation counter.

\section{Chromatographi Methods}

HPLC was carried out on a column $(0.4 \times 25 \mathrm{~cm})$ packed with silica gel, MICSI-10 (Kyowa Seimitsu Co., Tokyo). The eluting solvents for free acids and methyl esters were hexane/2-propanol/acetic acid (989:10:1) and hexane/2-propanol (124:1), respectively. The effluent was monitored by a UV detector KLC-2235 (Kyowa Seimitsu) at 234 or $275 \mathrm{~nm}$.

Thin layer chromatography (TLC) was done on plates coated with Wakogel B-0 (Wako Pure Chem. Ind., Osaka) and developed with hexane/ diethyl ether $(1: 1)$. Spots were visualyzed as described previously. ${ }^{8}$

Gas liquid chromatography (GC) was performed on a JEOL $20 \mathrm{~K}$ gas chromatograph equipped with a flame ionization detector and a stainless steel column ( $3 \mathrm{~mm} \times 1 \mathrm{~m}$ ) packed with $1 \%$ OV-17 on Chromosorb W (60/80 mesh). Column temperature was kept at $165^{\circ} \mathrm{C}$. Hydroxyl groups in the samples were converted to TMS-ether with TMS-BA (Tokya Kasei) just prior to injection. The relative retention time was expressed as a chain length of the corresponding saturated fatty methyl ester.

\section{Spectroscopic Analyses}

Ultra violet (UV) and IR spectra were recorded in ethanol and $\mathrm{CCl}_{4}$ solutions respectively. $\mathrm{GC}$ MS were conducted on a HITACHI M-52 equipped with a column of $2 \%$ OV-1. Ionization voltage was $25 \mathrm{eV}$. Nuclear magnetic resonance (NMR) spectra were recorded on a VARIAN $\mathrm{XL}-200$ spectrometer at $200 \mathrm{MHz}$ in $\mathrm{CDCl}_{3}$ solution with tetramethylsilane as an internal reference.

\section{Experiment $I I$ \\ Administration of $\mathrm{U}^{\mathrm{it}} \mathrm{C}-\mathrm{MLHPO}$ and $13-\mathrm{LAHPO}$ to Carp \\ U $-{ }^{14} \mathrm{C}-\mathrm{MLHPO} \quad(1.4 \mu \mathrm{Ci} / \mathrm{mmol}$; purity $98 \%)$} was prepared as described previously ${ }^{3)}$ and administered orally in a dose of $0.1 \mathrm{ml}$ per $100 \mathrm{~g}$ of body weight to 4 carp which had been bred with a commercial pellet ration for 3 months at $25^{\circ} \mathrm{C}$, under light anesthetization in MS 222 solution (200 ppm) by the method of Tsuchiya and Kayama. ${ }^{9)}$ The average weight of the carp was $224 \mathrm{~g}$. In the controlled experiment, $\mathrm{U}-{ }^{14} \mathrm{C}$ methyl linoleate $(\mathrm{ML}, 1.7 \mu \mathrm{Ci} / \mathrm{mmol})$ was given to 2 carp in the same manner. The carp were killed at $24 \mathrm{~h}$ after the administration and several organs were excised. The lipids were extracted by the method of Bligh and Dyer, ${ }^{8)}$ and the radioactivity was assayed with a liquid scintillation counter.

For GC-MS analysis, 13-LAHPO was also administered to 3 carp with the average weight of $237 \mathrm{~g}$ in a dose of $50 \mathrm{mg}$ per carp. After $8 \mathrm{~h}$, intestines were removed and the contents were rinsed throughly with physiological saline. The intestinal lipids were extracted as described above.

\section{Chromatographic Analysis of Some Organ Lipids}

The organ lipids were treated with diazomethane to esterify containing free fatty acids and then transmethylated with $0.5 \mathrm{~N}$ sodium methoxide in 
$\mathrm{CHCl}_{3} /$ methanol $(1: 1)$ for $10 \mathrm{~min}$ at room temperature. The resultant polar fatty methyl esters were concentrated using a Sep-Pak Cartridge Silica (Waters). About $100 \mathrm{mg}$ of methylated lipids were applied to a cartridge with $1 \mathrm{ml}$ of hexane/diethyl ether $(9: 1)$ and then unoxidized esters were removed with the additional $4 \mathrm{ml}$ of the same solvent. The polar esters were recovered with $10 \mathrm{~m} l$ of diethyl ether/methanol (1:9). The polar esters obtained from the lipids extracted from hepatopancreas, kidney and adipose tissues were chromatographed on silica gel plates as described above. The developed plates were divided into 21 parts with an equal width and the radioactivities were determined for each scarped fraction.

Methyl hydroxyoctadecadienoate (MHOD) and methyl oxooctadecadienoate (MOOD) were quantitatively analyzed by HPLC. MHOD and MOOD were determined from the absorptions at 233 and $275 \mathrm{~nm}$ for conjugated diene and conjugated oxodiene functions respectively. The amount of these two types of oxygenated esters were calculated from the absorption coefficients obtained from the authentic MHOD and MOOD which had been prepared by the reduction of LAHPO with $\mathrm{NaBH}_{4},{ }^{02}$ and by the successive oxidation of MHOD with $\mathrm{CrO}_{3}$-pyridine complex, ${ }^{10)}$ respectively. Both compounds were purified by dry silica gel column chromatography using hexane/ diethyl ether (7:3) as the eluting solvent.

The lipids extracted from intestines of carp administered 13-LAHPO were treated in the same manner as described above and the consequent polar esters were subjected to dry silica gel column chromatography with the linear gradient elution mentioned in Exp. I. The fractions which showed an UV absorption at 233 or $275 \mathrm{~nm}$ were analyzed by GC-MS. Other chromatographic or spectroscopic analytical conditions are the same as described for Exp. I.

\section{Results}

Isolation of the Decomposition Products of LAHPO in Vitro

Fig. 1 shows the column chromatographic separation of the methyl esterified products formed from $\mathrm{U}^{14} \mathrm{C}-13$-LAHPO in the reaction with the carp intestinal acetone powder. The products were separated into four major fractions, i.e., I to IV. The recovery of the radioactivity from the column reached $93.7 \%$, which corresponded to

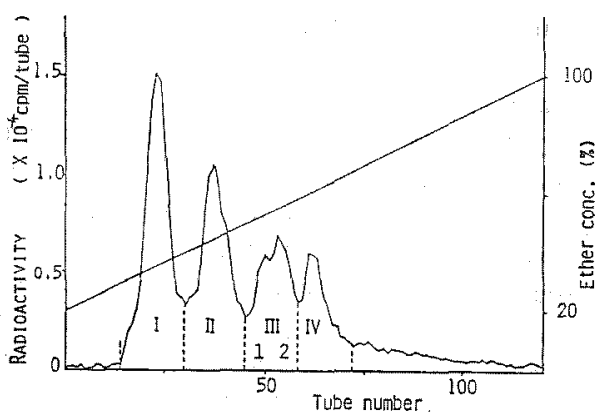

Fig. 1. Radiochromatogram of methyl esters of oxygenated fatty acids isolated after incubation of $\mathrm{U}-{ }^{4} \mathrm{C}-13-\mathrm{LAHPO}$ with the carp intestinal acetone powder.

Column: Silica Woelm TSC, $1.2 \times 125 \mathrm{~cm}$. Solvent: Concentration of ether in hexane was linearly increased from 20 to $100 \%$.

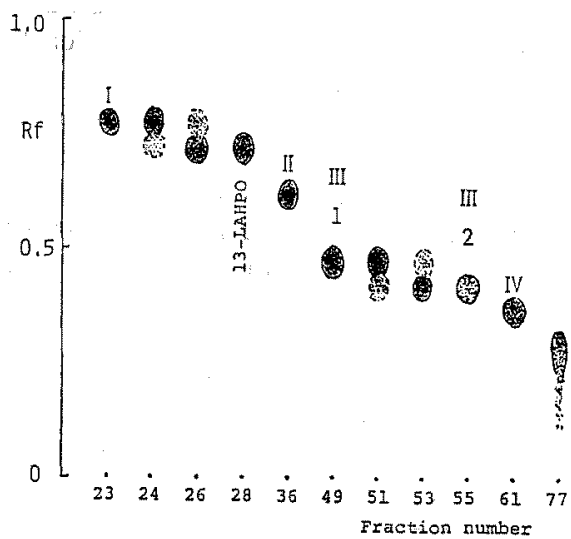

Fig. 2. TLC of silica gel column chromatographic fractions.

Plate: Wakogel B-0. Solvent: Hexane/Ether (1:1). Developed twice.

$78.4 \%$ of the activity of the reacted $\mathrm{U}_{-14}{ }^{14} \mathrm{C}$-LAHPO. The components of major fractions were analyzed by TLC (Fig. 2). Fraction I was found to contain undecomposed 13-MLHPO (Rf. 0.72) together with a reaction product with Rf. 0.77. HPLC completely separated the product from 13-MLHPO, and the product consisted of two components, I-1 and I-2. Both could be detected by monitoring the absorption at $275 \mathrm{~nm}$. Fraction III also consisted of two components, i.e., III-1 and III-2, which showed slightly different Rf. values, 0.47 and 0.42 on TLC respectively (Fig. 2), whereas both of the fractions, II and IV, gave a single spot with $\mathrm{Rf}$. values with 0.62 and 
0.37 on TLC respectively.

\section{Structures of Products $I-1$ and $1-2$}

Both products I-1 and I-2 were positive with 2,4-dinitrophenylhydrazine reagent on TLC, therefore, these products are suggested to be carbonyl compounds. Their UV spectra, which showed an absorption maximum at 277 or $275 \mathrm{~nm}$ respectively in EtOH, suggested the occurrence of conjugated oxodiene chromophore in their molecule. Both $\mathrm{I}-1$ and -2 gave a single peak at C20.1 (I-1) and C20.9 (I-2) on GC. MS of these two peaks were essentially identical and major ion peaks were as follows: $\mathrm{m} / \mathrm{e} ; 308(\mathrm{M}), 277(\mathrm{M}-$ $\left.\mathrm{OCH}_{3}\right), 252\left(\mathrm{M}-\mathrm{CH}_{2}=\mathrm{CHCH}_{2} \mathrm{CH}_{3}\right), 237[\mathrm{M}-$ $\left.\left(\mathrm{CH}_{2}\right)_{4} \mathrm{CH}_{3}\right], 209\left[\mathrm{M}-\mathrm{CO}\left(\mathrm{CH}_{2}\right)_{4} \mathrm{CH}_{3}\right], 177(\mathrm{M}-$ $\left.\mathrm{CH}_{3} \mathrm{OH}\right)$ and $151 \quad\left[(\mathrm{CH}=\mathrm{CH})_{2} \mathrm{CO}\left(\mathrm{CH}_{2}\right)_{4} \mathrm{CH}_{3}\right]$. The MS fragments compared favorably with those reported by Hamberg ${ }^{11)}$ for methyl 13-oxo-9,11octadecadienoate. IR spectra of I-1 and I-2 were quite similar to each other and almost identical with that of methyl 9-oxo-trans-10,trans-12octadecadienoate reported by Vioque and Holman ${ }^{12)}$ except that an absorption at $955 \mathrm{~cm}^{-1}$ was observed with the same intensity as that at $990 \mathrm{~cm}^{-1}$ in the spectrum of I-1. These combined data suggested that I-1 and I-2 are geometric isomers of 13-oxo-9,11-octadecadienoate, i.e., I-1 is cis, trans-, while I-2 is trans, trans-isomer. The oxo derivative prepared from 13-LAHPO by the successive reduction with $\mathrm{NaBH}_{4}$ and oxidation with $\mathrm{CrO}_{3}$-pyridine complexes showed identical features with I-1 on HPLC, GC, IR and MS. Therefore, products I- 1 and I-2 were identified as cis, trans and trans, trans isomers of methyl 13-oxo- 9,11-octadecadienoate, respectively. The ratio of I-1 to I-2 was 3: 1 determined by HPLC.

\section{Structure of Production II}

The UV spectrum of product II showed an absorption maximum at $233 \mathrm{~nm}$ indicating the retaining of a conjugated diene moiety in the molecule. IR spectrum suggested the occurrence of hydroxy group(s) by the absorption at 3600 $\mathrm{cm}^{-1}$ and conjugated cis, trans diene by 990 and $950 \mathrm{~cm}^{-1}$ respectively. GC of the TMS-derivative of II gave a single peak at C19.8 and MS of this peak showed the characteristic fragments for methyl 13-OTMS-9,11-octadecadienoate as follows: $\mathrm{m} / \mathrm{e} ; 382(\mathrm{M}), 311\left[\mathrm{M}-\left(\mathrm{CH}_{2}\right)_{4} \mathrm{CH}_{3}\right], 225$ $\left[\mathrm{M}-\left(\mathrm{CH}_{2}\right)_{4} \mathrm{COOCH}_{3}\right]$. The intensity of the peak with $\mathrm{m} / \mathrm{e} 311$ was twice as large as that with $\mathrm{m} / \mathrm{e}$ 225 , suggesting the location of a hydroxy group at $C-13 .^{13)}$ All these data showed good agreement with those obtained from the hydroxy derivative prepared from 13-LAHPO by the reduction with $\mathrm{NaBH}_{4}$. Thus product II was identified as methyl 13-hydroxy-cis-9, trans-13-octadecadienoate.

\section{Structures of Products III-1 and III-2}

Products III-1 and III-2 showed no absorption maximum in the range of $220-370 \mathrm{~nm}$. GC gave a single peak with the same retention time for III-1 and III-2 at C21.3. MS of these two products were also similar to each other, and included char. acteristic ion peaks at $\mathrm{m} / \mathrm{e} ; 383\left(\mathrm{M}-\mathrm{CH}_{3}\right), 327$ $\left[\mathrm{M}-\left(\mathrm{CH}_{2}\right)_{4} \mathrm{CH}_{3}\right]$ and $285\left[\mathrm{M}-\mathrm{CH}-\mathrm{CH}\left(\mathrm{CH}_{2}\right)_{4} \mathrm{CH}_{3}\right]$.<smiles>C1COC1</smiles>

These fragments were essentially identical to the

Table 1. ${ }^{1} \mathrm{H}-\mathrm{NMR}$ of compounds III-1 and III-2 (methyl 11-hydroxy-12,13-epoxy-9-octadecenoate)

$$
\mathrm{CH}_{3}-\left(\mathrm{CH}_{2}\right)_{3}-\mathrm{CH}_{2}-\mathrm{CH}_{2}^{\mathrm{a}}-\mathrm{CH}-\mathrm{C}-\mathrm{CH}-\mathrm{CH}=\stackrel{\mathrm{f}}{\mathrm{f}}-\mathrm{CH}_{2}^{\mathrm{g}}-\left(\mathrm{CH}_{2}\right)_{6}-\mathrm{COOCH}_{3}
$$

\begin{tabular}{|c|c|c|c|c|c|c|c|}
\hline & \multicolumn{7}{|c|}{ Compound III-1 } \\
\hline $\mathrm{H}$ & $\mathrm{a}$ & $b$ & $\mathrm{c}$ & $\mathrm{d}$ & $\mathrm{e}$ & f & $\mathrm{g}$ \\
\hline$\delta(\mathrm{ppm})$ & - & $3.01(1 \mathrm{H})$ & $2.79(1 \mathrm{H})$ & $4.67(1 \mathrm{H})$ & $5.34(1 \mathrm{H})$ & $5.65(1 \mathrm{H})$ & $2.09(2 \mathrm{H})$ \\
\hline \multirow[t]{3}{*}{$\mathrm{J}(\mathrm{Hz})$} & $J_{\mathrm{Ab}} 5$ & $J_{b a} 5$ & $\mathrm{~J}_{e \mathrm{~b}} 2$ & $\mathbf{J}_{\mathrm{dc}} 3$ & $\mathrm{~J}_{\mathrm{ed}} \quad 9$ & $J_{f \theta} 11$ & $\mathbf{J}_{\mathrm{g} \boldsymbol{}} 8$ \\
\hline & & $J_{b c} 2$ & $J_{\text {ed }} 3$ & $J_{d e} \quad 9$ & $\mathbf{J}_{\mathrm{ef}} \quad 11$ & $\begin{array}{ll}J_{f g} & 8\end{array}$ & \\
\hline & \multicolumn{7}{|c|}{ Compound III-2 } \\
\hline $\mathbf{H}$ & a & $\mathrm{b}$ & c & $d$ & $\mathrm{e}$ & f & $\mathrm{g}$ \\
\hline$\delta(\mathrm{ppm})$ & - & $2.94(1 \mathrm{H})$ & $2.80(1 \mathrm{H})$ & $4.28(1 \mathrm{H})$ & $5.49(1 \mathrm{H})$ & $5.59(1 \mathrm{H})$ & $2.09(2 \mathrm{H})$ \\
\hline $\mathrm{J}(\mathrm{Hz})$ & $J_{a b} 6$ & $\begin{array}{ll}J_{\mathrm{ba}} & 6 \\
\mathbf{J}_{\mathrm{bc}} & 2.5\end{array}$ & $\begin{array}{ll}\mathrm{J}_{\mathrm{cb}} & 2.5 \\
\mathrm{~J}_{\mathrm{cd}} & 5\end{array}$ & $\begin{array}{ll}\mathrm{J}_{\mathrm{dc}} & 5 \\
\mathrm{~J}_{\mathrm{dc}} & 8\end{array}$ & $\begin{array}{lr}\mathbf{J}_{\text {ed }} & 8 \\
\mathbf{J}_{\mathrm{ef}} & 11\end{array}$ & $\begin{array}{lr}\mathrm{J}_{\mathrm{fe}} & 11 \\
\mathrm{~J}_{\mathrm{fg}} & 6\end{array}$ & $J_{E P} 6$ \\
\hline
\end{tabular}


spectrum reported for methyl 11-OTMS-12,13epoxy-9-octadecenoate. ${ }^{14)}$

The difference in the structures between III-1 and III-2 was demonstrated in their ${ }^{1} \mathrm{H}-\mathrm{NMR}$ spectra (Table 1). III-1 gave an identical spectrum to the data presented for erythro-11-hydroxytrans-12,13-epoxy-cis-9-octadecenoate, ${ }^{15}$, while the spectrum of III-2 was well compared to the data reported for the threo form. ${ }^{18)}$ Consequently, III-1 and III-2 were identified as methyl erythro and threo-11-hydroxy-trans-12,13-epoxy-cis-9-octadecenoates respectively.

\section{Structure of Product IV}

The TMS derivative of IV gave a single peak on GC with C22.2. GC-MS m/e of this fraction after silylation: $398(\mathrm{M}), 383\left(\mathrm{M}-\mathrm{CH}_{8}\right), 327$ $\left[\mathrm{M}-\left(\mathrm{CH}_{2}\right)_{4} \mathrm{CH}_{3}\right], 259\left[\mathrm{CHOTMS}\left(\mathrm{CH}_{2}\right)_{7} \mathrm{COOCH}_{3}\right]$, $241\left[\mathrm{M}-\left(\mathrm{CH}_{2}\right)_{7} \mathrm{COOCH}_{3}\right]$. These fragment peaks are in favorable accordance with the characteristic mass fragments for methyl 9-OTMS-12,13epoxy-10-octadecenoate reported by Hamberg. ${ }^{11)}$

${ }^{1} \mathrm{H}-\mathrm{NMR}$ spectrum indicated the presence of a trans epoxide and a trans olefin with absorptions at $5.45(1 \mathrm{H})$ and $5.94(1 \mathrm{H})$. These data were in good accordance with those presented for methyl 9-hydroxy-trans-12, 13-epoxy-trans-10-octadecenoate by Gardner et al. ${ }^{17)}$

The decomposition products of 13-LAHPO identified in the present study are summarized in Fig. 3. These four products occupied approximately $75 \%$ of the decomposed substrate. The remainder was mainly contained in the polar fraction recovered with methanol from silica gel columns.

$$
\begin{array}{lll}
\text { I } \mathrm{CH}_{3}-\left(\mathrm{CH}_{2}\right)_{4}-\hat{\mathrm{C}}-\mathrm{CH}=\mathrm{CH}-\mathrm{CH}=\mathrm{C}=\mathrm{CH}-\left(\mathrm{CH}_{2}\right)_{7}-\mathrm{COOH} & (15.4 \%) \\
\text { II } \mathrm{CH}_{3}-\left(\mathrm{CH}_{2}\right)_{4}-\mathrm{CH}-\mathrm{CH}-\mathrm{CH}=\mathrm{CH}-\mathrm{CH}=\mathrm{CH}-\left(\mathrm{CH}_{2}\right)_{7}-\mathrm{COOH} & (25.5 \%) \\
\text { III } \mathrm{CH}_{3}-\left(\mathrm{CH}_{2}\right)_{4}-\mathrm{CH}-\mathrm{CH}-\mathrm{CH}-\mathrm{CH}=\mathrm{CH}-\left(\mathrm{CH}_{2}\right)_{7}-\mathrm{COOH} & (20.3 \%) \\
\text { N } \mathrm{CH}_{3}-\left(\mathrm{CH}_{2}\right)_{4}-\mathrm{CH}-\mathrm{CH}-\mathrm{CH}=\mathrm{CH}-\mathrm{CH}-\left(\mathrm{CH}_{2}\right)_{7}-\mathrm{COOH} \quad(14.2 \%)
\end{array}
$$

Fig. 3. Structures of the decomposition products derived from 13-LAHPO incubated with the carp intestinal acetone powder.

I: 13-Oxo-cis(trans)-9,trans-11-octadecadienoic acid. II: 13-Hydroxy-cis-9,trans-11-octadecadienoic acid. III: 11-Hydroxy-trans-12,13epoxy-cis-9-octadecenoic acid. IV: 9-Hydroxytrans-12,13-epoxy-trans-10-octadecenoic acid. The figures in parenthesis represent the percentage distribution of each product against the decomposed substrate. The remainder $(24.6 \%)$ consisted of unidentified polar substances.

\begin{tabular}{|c|c|c|c|c|}
\hline & \multicolumn{2}{|c|}{$\begin{array}{c}\text { Specific } \\
\text { activity*1 } \\
\left(\times 10^{4} \mathrm{dpm} / \mathrm{g}\right. \\
\text { lipids })\end{array}$} & \multicolumn{2}{|c|}{$\begin{array}{c}\text { Distribution of } \\
\text { radioactivity } \\
(\%)\end{array}$} \\
\hline & ML & MLHPO & $\mathrm{ML}$ & MLHPO \\
\hline Muscle and skin & 9.1 & 24.6 & 23.4 & 21.1 \\
\hline Hepatopancreas & 98.7 & 6.3 & 8.5 & 4.0 \\
\hline Kidney & $\$ 9.0$ & 24.6 & 2.1 & 5.5 \\
\hline Intestine & 24.7 & 6.8 & 3.1 & 5.1 \\
\hline Intestinal contents & 90.0 & 18.2 & 0.4 & 1.4 \\
\hline Adipose tissue & 85.7 & 4.6 & 26.8 & 11.3 \\
\hline Gill & 31.2 & 3.4 & 2.1 & 0.9 \\
\hline Other viscera & 79.0 & 40.4 & 13.7 & 30.0 \\
\hline Blood*2 & 38.8 & 1.5 & 3.8 & 0.8 \\
\hline Others & 3.1 & 1.1 & 16.1 & 25.9 \\
\hline
\end{tabular}

Table 2. Distribution of the radioactivity to organ lipids of the carp administered $\mathrm{U}^{14} \mathrm{C}-\mathrm{ML}$ or -MLHPO

\section{Experiment II}

Table 2 shows the specific radioactivity of lipids extracted from each organ and the distribution of radioactivity $24 \mathrm{~h}$ after the administration of $\mathrm{U}^{14} \mathrm{C}-\mathrm{ML}$ and $\mathrm{U}-{ }^{14} \mathrm{C}-\mathrm{MLHPO}$ to carp. Total recovery of the radioactivity was $29.8 \%$ for ML and $8.3 \%$ for MLHPO. In carp given ML, the specific activity was relatively high in hepatopancreas, adipose tissues and "other viscera." In MLHPO-supplemented groups, the lipids in "other viscera" and kidney showed remarkablly high incorporations of the radioactivity judging from the specific activity, although the distribution of radioactivity was apparently higher in tissues with big masses such as adipose tissues, muscles and skin.

In order to estimate what kind of substances retained the radioactivity, the polar methyl esters prepared from hepatopancreas, kidney and adipose tissues were developed on silica gel plates and the distribution of the radioactivity was compared with the decomposition products of LAHPO in the reaction with carp intestinal acetone powder after methyl esterification (Fig. 4). Recoveries of the radioactivity in the polar ester fraction against the total radioactivity of the lipids in hepatopancreas, kidney and adipose tissues were $86.4,91.8$ and $95.5 \%$, respectively.

As shown in Fig. 4, the profiles of the chromatograms obtained from three different tissues were very similar to that of the in vitro control, and the higher distribution of radioactivity was observed at the region corresponding to MOOD, 


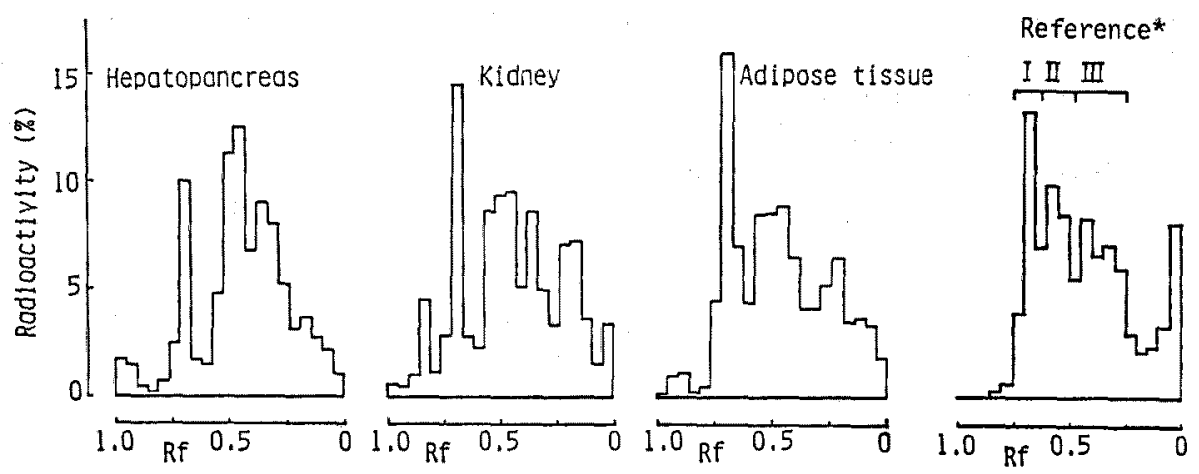

Fig. 4. Radio-TLC of methylesterified lipids extracted from some organs of the carp administered U- ${ }^{14}$ C-MLHPO. See Fig. 2. for TLC conditions.

* The chromatogram of methylesterified decomposition products of $\mathrm{U}^{14}-\mathrm{C}-\mathrm{LAHPO}$ after incubation with the carp intestinal acetone powder. I: Methyl oxooctadecadienoate. II: Methyl hydroxyoctadecadienoate. III: Methyl hydroxyepoxyoctadecenoate.

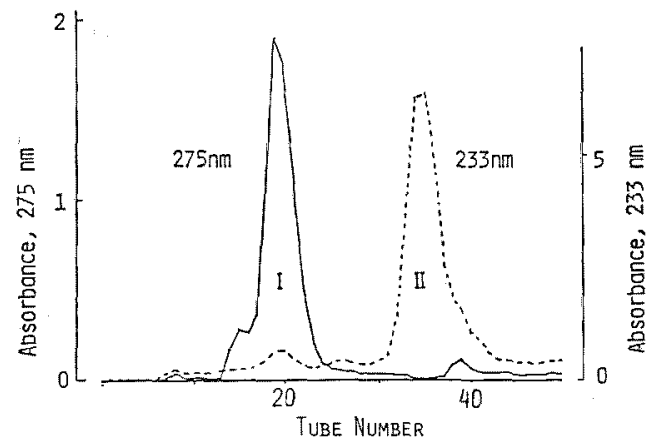

Fig. 5. Dry column chromatography of methylesterified lipids extracted from the intestine of the carp administered 13-LAHPO.

MHOD and hydroxy epoxy esters. These observations were further confirmed by column chromatographic and GC-MS analyses. Fig. 5 demonstrates the dry silica gel column chromatograms of the polar ester fraction extracted and prepared from the intestine of carp at $8 \mathrm{~h}$ after the administration of 13-LAHPO. By monitoring with UV absorptions at 233 (II) and 275 (I) nm, two distinct peaks were observed at the fractions corresponding to hydroxy and oxo esters in Experiment I (Fig. 1).

GC and GC-MS analyses revealed from the retention time and mass fragments that the components of peaks I and II on dry column chromatography are methyl 13-oxo-9,11-octadecadienoate and methyl 13-hydroxy-9,11-octadecadienoate. Although hydroxy epoxy esters were expected to be contained in the fractions following to peak II, GC-MS analysis for those fractions could not prove the presence of them because of the severe contamination with cholesterol.

The amount of MHOD and MOOD incorporated into some organs by the administration of MLHPO was assayed by HPLC. Fig. 6 shows the chromatogram of polar esters in kidney lipids with authenic MLHPO, MOOD and MHOD. The series of peaks corresponding to MOOD and MHOD were observed in kidney lipids, while MLHPO was completely absent. Table 3 shows the percentage distribution of MOOD and MHOD in lipids of several organs against the total MLHPO incorporated into each organ calculated from the radioactivity. Both of MOOD and MHOD were found in all of the organs analyzed, and 10 to $26 \%$ of administered MLHPO was recovered as MOOD, while 23 to $37 \%$ was characterized as MHOD, whereas MLHPO could not be detected in all tissues except for adipose tissues in which a trace peak was recognized in the fraction corresponding to MLHPO.

\section{Discussion}

Many workers have reported on the decomposition products of LAHPO in the reactions with several enzymatic catalysts such as LAHPO isomerase, ${ }^{18,10)}$ lipoxygenase, ${ }^{12,20,21)}$ soybean extract, ${ }^{17,22)}$ wheat flour, ${ }^{23)}$ and potato tubers, ${ }^{18)}$ or nonenzymatic model systems including $\mathrm{FeCl}_{s}$ cysteine, ${ }^{13,17,24,25)}$ and hemoglobin. ${ }^{112}$ Except for LAHPO isomerase and hydroperoxide lyase, the decomposition products include various oxygenated secondary products such as hydroxydiene, oxodiene, hydroxyepoxymonoene, oxoepoxy- 


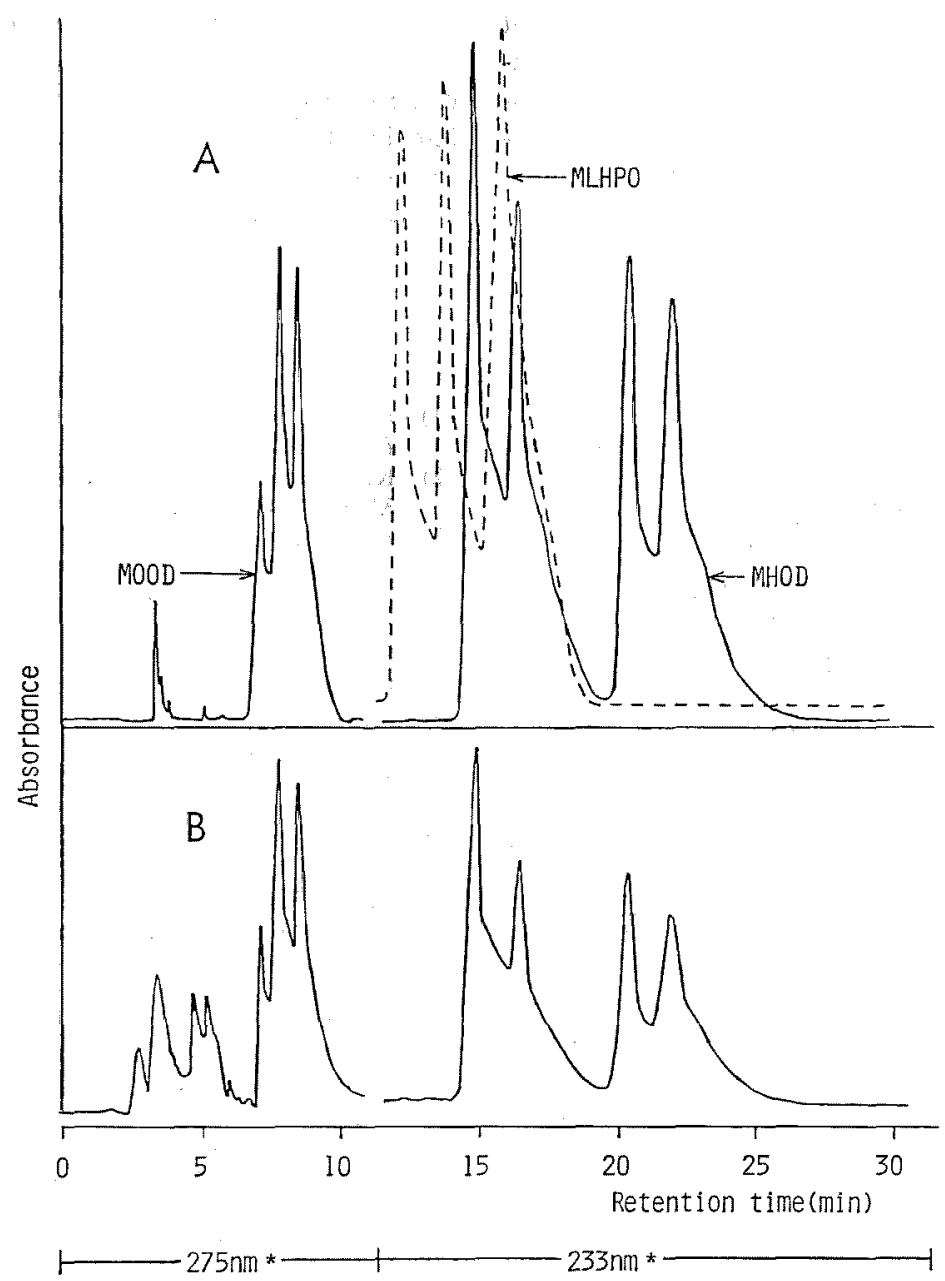

Fig. 6. HPLC of the authentic MOOD, MHOD and MLHPO (A) and the methyl esters of oxygenated fatty acids prepared from the kidney lipids of the carp administered MLHPO (B).

* The eluents were monitored at the wave length indicated.

Table 3. Ratio of oxo and hydroxy derivatives to the incorporated radioactivity in carp organ lipids at $24 \mathrm{~h}$ after the oral administration of $\mathrm{U}^{-14} \mathrm{C}$ MLHPO

\begin{tabular}{lrc}
\hline & MOOD & MHOD \\
\hline Hepatopancreas & 14.3 & 32.9 \\
Kidney & 19.4 & 31.1 \\
Intestine & 9.6 & 37.3 \\
Adipose tissues & 26.3 & 36.2 \\
Other viscera & 21.8 & 22.6 \\
\hline
\end{tabular}

monoene, hydroperoxyepoxymonoene, oxohydroxymonoene and trihydroxymonoene. In the present study, four major substances shown in Fig. 3 were identified as the decomposition pro- ducts of LAHPO by carp intestinal acetone powder and this composition of the degradation products were very similar to that formed by the reaction with hemoglobin reported by Hamberg, ${ }^{11)}$ although the geometric configuration of olefin and epoxide were not studied in his work. Previously the authors suggested that the substances other than heme compounds should be involved in the decomposition of LAHPO with the carp intestinal extract because the addition of cyanide revealed only a partial inhibition to this reaction. ${ }^{32}$

Although the properties of the substance(s) responsible for decomposing of LAHPO in carp intestine have not been clarified so far, it is presumed that LAHPO was decomposed preferentially 
by heme compounds in the system without cyanide, or the substances other than heme compounds decompose LAHPO by the same mechanism with hemoglobin. In any case it is interesting that the composition of the decomposition products was much simpler in the complicated biological systems of carp intestine than in the simple model system of $\mathrm{FeCl}_{3}$-cysteine, or high temperature treatment. ${ }^{14}$ )

In Experiment II, U-14 C-labeled MLHPO and ML were orally administered to carp and the incorporation of the radioactivity into some organs were followed together with the decomposition pathway of MLHPO. Comparing the absorbability of MLHPO with ML, the recovery of the radioactivity in the carp fed MLHPO was far lower than that fed ML. The distribution of the radioactivity in the body was also different between two groups. These data indicated that the absorption process of MLHPO was different from that of ML as suggested by Takeuchi.") The total recovery of the radioactivity from the whole body and the distribution in hepatopancreas in the MLHPO-administered carp were much lower in our study than those reported by Takeuchi, ${ }^{\text {s) }}$ The prime factors causing such a distinct disagreement are still ambiguous, however, the differences in the experimental conditions such as the position of the labeled carbon in MLHPO $\left(1-{ }^{14} \mathrm{C}-\mathrm{MLHPO}\right.$ by Takeuchi), the diets and the administration method of MLHPO are suggested to be involved.

Chromatographic analyses of the polar esters in several organs of carp administered MLHPO revealed that MOOD and $\mathrm{MHOD}$ are the major secondary products derived from MLHPO, and they occupied approximately half of the recovered radioactivity. In case of rodents, ${ }^{2,26)}$ a part of orally administered MLHPO was absorbed from the intestine without any modification and incorporated in various tissues such as the liver. However, in carp, MLHPO was almost completely absent in the body lipids even in the lipids extracted from the intestinal wall at $8 \mathrm{~h}$ after the administration (Fig. 5). These results are in good accordance with our previous observations that the accumulation of peroxides was not recognized in carp fed MLHPO, whereas the carbonyl value of tissue lipids significantly increased. ${ }^{1)}$ MOOD is presumed to be one of the major carbonyl compounds derived from MLHPO in carp.

From these observations, the authors conclude that the MLHPO administered orally to carp is incorporated after the decomposition to secondary products such as hydroxyoctadecadienoate, oxooctadecadienoate and hydroxyepoxyoctadecenoate into intestinal tissues. This result indicates that the toxic effects of lipid peroxides produced in the diets would be mainly caused by such decomposition products of lipid peroxides.

\section{References}

1) K. Hata and T. Kaneda: Bull. Japan. Soc. Sci. Fish., 46, 997-1000 (1980).

2) K. Nakatsugawa and T. Kaneda: Yukagaku, 32, 361-366 (1983).

3) K. Hata, M. Tanno, and T. Kaneda: Bull. Japan. Soc. Sci. Fish., 47, 51-56 (1981).

4) E. G. Hrycay and P. J. O'Brien: Arch. Biochem, Biophys., 157, 7-22 (1973).

5) M. Takeuchi: Bull. Japan. Soc. Sci. Fish., 38, 155-159 (1972).

6) M. Hamberg and B. Samuelsson: J. Biol. Chem., 242, 5329-5335 (1967).

7) H. W. S. Chan and G. Levett: Lipids, 12, 99-104 (1977).

8) E. G. Bligh and W. J. Dyer: Can. J. Biochem. Physiol., 37, 911-917 (1959).

9) Y. Tsuchiya and M. Kayama: Tohoku J. Agr. Res., 9, 41-52 (1958).

10) C. R. Smith, Jr., T. L. Wilson, E. H. Melvin, and I. A. Wolff: J. Am. Chem. Soc., 82, 1417-1421 (1960).

11) M. Hamberg: Lipids, 10, 87-92 (1975).

12) E. Vioque and R. T. Holman: Arch. Biochem. Biophys., 99, 522-528 (1962).

13) R. Kleiman and G. F. Spencer: J. Am. Oil Chem. Soc., 50, 31-38 (1973).

14) M. Hamberg and B. Gotthammar: Lipids, 8, 737-744 (1973).

15) H.W. Gardner and R. Kleiman: Biochim. Biophys. Acta, 665, 113-125 (1981).

16) T. Galliard, D. R. Phillips, and J. A. Matthew: Biochim. Biophys. Acta, 409, 157-171 (1975).

17) H. W. Gardner, D. Weisleder, and R. Kleiman: Lipids, 13, 246-252 (1978).

18) D.C. Zimmerman and B. A. Vick: Plant Physiol., 46, 445-453 (1970).

19) H.W. Gardner: J. Lipid Res, 11, 311-321 (1970).

20) G. J. Garssen, J. E. G. Vliegenthart, and J. Boldingh: Biochem. J., 122, 327-332 (1971).

21) G.J. Garssen, G.A. Veldink, J.E.G. Vliegenthart, and J. Boldingh: Eur. J. Biochem., 62, 33-36 (1976).

22) H. W. Gardner and R. Kleiman: Lipids, 12, 941944 (1977).

23) A. Graveland: J. Am. Oil Chem. Soc., 47, 352361 (1970).

24) H. W. Gardner, R. Kleiman, and D. Weisleder: Lipids, 9, 696-706 (1974).

25) H. W. Gardner and C. G. Crawford: Biochim. Biophys. Acta, 665, 126-133 (1981).

26) K. Nakatsugawa and T. Kaneda: Yukagaku, 30, 74-77 (1981). 